\title{
Preparation, Characterization and Properties of some Acrylic Base Latex: (A-Review)
}

\section{SATISH KUMAR ${ }^{1 *}$, SHAYORAJ ${ }^{1}$, NEERU DEVI', SANTOSH KUMAR DUBEY ${ }^{1}$, ASHWANI KUMAR ${ }^{2}$, SURESH KUMAR ${ }^{3}$ and KAPIL GULATI ${ }^{4}$}

\author{
'Department of Chemistry, Institute of Integrated \& Honors Studies, Kurukshetra University Kurukshetra, \\ Haryana-136119, India. \\ ${ }^{2}$ Department of Chemistry, Kurukshetra University Kurukshetra, Haryana-1361193, India. \\ ${ }^{3}$ Department of Chemistry, Kurukshetra University Kurukshetra, M.N. College, \\ Shahbad Haryana-136135, India. \\ ${ }^{4}$ Department of Chemistry, Kurukshetra University Kurukshetra, Dyal Singh College, \\ Karnal Haryana-132001, India. \\ ${ }^{*}$ Corresponding author E-mail: satishkumar@kuk.ac.in
}

http://dx.doi.org/10.13005/ojc/370501

(Received: September 13, 2021; Accepted: October 15, 2021)

\section{ABSTRACT}

Acrylic polymer latex has versatile role in many academic and industrial applications like paint, adhesives, textile, paper industry, concrete, surface coating, synthetic rubber and many ones. Acrylic base polymer latex can be prepared by various polymerization methods like Batch emulsion, Seeded emulsion, Situ miniemulsion, Atom transfer radical, Free radical copolymerization, Pickering miniemulsion, Semi-continuous seeded emulsion, dispersion copolymerization, aqueous suspension polymerization etc. in different solvents i.e. 1,1,2-trichloroethane, water, deionized water, 1,4-dioxane, chloroform, tetra hydro furan, toluene, benzene, nitric acid and so on. Acrylic latexes possessed various properties such as increased particle size which resist centrifugal nature and reduce viscosity of heavy oil, layered coating on steel improve lustre along with flexibility, tensile strength and thermal stability too. Acrylic latexes increase silicon intensity in silicon nanoparticles by controlling $\mathrm{pH}$ of emulsion during polymerization and also super paramagnetic behaviour of $\mathrm{Fe}_{2} \mathrm{O}_{3}$ nanocomposites latex controlled by $\mathrm{pH}$. In this connection, many researchers have synthesized various acrylic base polymer latex or its composites, investigate its utility in different forms for different purposes to improve properties as required. In this review our main emphasis is to investigate the synthesis, characterisation and application of various acrylate polymer latexes.

Keyword: Polymerization techniques, Emulsion, Acrylate, Latex, Nano-composites, Thermal techniques.

\section{INTRODUCTION}

In many manufacture processes, acrylic based polymer latex has significant role in synthetic rubber, surface coatings, adhesives, paper, textile additives are manufacture by latex. Acrylic based

This is an Open Access article licensed under a Creative Commons license: Attribution 4.0 International (CC- BY). Published by Oriental Scientific Publishing Company @ 2018

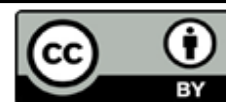


polymer latex raw materials are mostly obtained from fossil resources. The excess use of fossils resources causes the hike in price of petroleum which leads to increase the research for alternate i.e. on renewable resources for acrylic latex processing. In this study, renewable and non-renewable, both resources are examined and summarized in the preparation of acrylic base polymer latex. The reason for literature survey is the use of various monomers in the preparation of latex based acrylic polymer and its composites. Various polymerisation techniques have been purposed for the synthesis of acrylic latex ${ }^{1-14}$. Polymerisation process can occur via free-radical mechanism using some methods i.e. suspension, emulsion polymerization and mass solution. Polymerization via emulsion is not normal since it is different method in which three separate sites are available where polymerization reactions can occur, first is in the continuous hydrous phase and second is on the surface of the lengthen particles, and third is inside the lengthen particles. This distinctive aspect of polymerisation emulsion provides a wide range of design options for various polymers and latexes. Like polymers which have high molecular-weight, even copolymers, hard-to-copolymer monomers with core copolymers, functional (surface modified) latexes, even size latex particles, grafted latex, core-shell, microdomain structures, multi-penetration polymers ${ }^{15-16}$. In this field many researchers suggest different ideas to improve the properties of acrylic latex by adding other functional monomers. In this review our main emphasis is to investigate the synthesis, characterisation and application of various acrylate polymer latexes and compare the physical properties of these latexes in hope for synthesis of better latex for future.

\section{Acrylic Polymer Latex Modified with Fluorine}

Yanjun has been prepared the fluorine inserted acrylate base latex through batch method which possesses self-linker properties with crosslinking agent like $\mathrm{N}$-hydroxymethyl acrylamide (NMA) ${ }^{17-18}$. He found all result were good in the strength of emulsion, such as stability in storage, stability of resistance in electrolyte and centrifugal stability. This study concluded that with enhance the amount of NMA, prepared sample attend high temperature area in glass transition temperature $(\mathrm{Tg})$, increased in the particle size of the latex, and enhanced the properties of latex film like thermal stabilities and solvent resistance. IR spectra of the prepared latex film (BA: MMA: NMA: Zonyl TM) shown the characteristic absorption peak at 1539 $\mathrm{cm}^{-1}$ due to $\mathrm{N}-\mathrm{H}$ bond appeared and the absorption peak due to $\mathrm{C}=\mathrm{C}$ bond of monomers at $1640 \mathrm{~cm}^{-1}$ was disappeared, indicating that the monomers had polymerized. These two results proved that Zonyl TM and NMA participated in the polymerization.

Researcher have been applying the seed emulsion polymerization technique i.e. for polyacrylate emulsion with fluorine was synthesized without emulsifier with the help of acrylate monomer like butyl acrylate (BA), methyl methacrylate (MMA), and hexafluoro butyl methacrylate (HFMA) using ammonium allyloxmethylate nonylphenol ethoxylates sulphate (DNS-86) as polymerizable emulsifier in this process ${ }^{19-20}$. In fluorine containing film, the concentration of fluorine and the hydrophobicity of film were calculated by X-ray photoelectron spectroscopy (XPS) and contact angle (CA) method. Additionally, thermogravimetry (TG) study concluded that the fluorine-free emulsion film has lesser aquaphobia capacity and less stable to heat when compared to fluorine containing emulsion film. Similarly, as mentioned ${ }^{7}$, IR spectra of emulsion films didn't show the characteristic absorption peak at $1640 \mathrm{~cm}^{-1}$ of $\mathrm{C}=\mathrm{C}$ bonds, indicating that the double bonds in the reactive monomers took part in the emulsion polymerization. IR peak at $890 \mathrm{~cm}^{-1}$ resulted from combination of rocking and wagging vibrations of CF2 groups, which did not appear in fluorine free acrylate copolymer emulsion film. IR spectra revealed that the HFMA had effectively participated in emulsion copolymerization.

Ling with his team has worked with the acrylate base monomers i.e. methyl meth acrylate (MMA), dodecafluoroheptyl methacrylate (DFHM), butyl acrylate (BA) for synthesis of latex ${ }^{21}$. They applied radical initiated seed emulsion polymerization and solution polymerization technique to synthesize fluorinated acrylic copolymer latex. With the help of lower molecular weight monomers, the copolymer latex of monomers like BA/MMA/DFHM was prepared as core-shell structure and the copolymer solution of poly BA/MMA/DFHM was formed. The fluorine element on the film surface was higher than theoretical value but was in proportion to the DFHM content. These results indicate that the surface properties of fluorinated latex were improved when coated on the surface of the film. FT-IR spectra 
obtained from core-shell BA/MMA/DFHM latex and poly (BA-MMA-DFHM) solution. The absorption at $970 \mathrm{~cm}^{-1}$ belonged to a representative peak of BA, stretching vibration and wagging vibration of $\mathrm{C}-\mathrm{F}$ bonds appeared at $1246 \mathrm{~cm}^{-1}$ and $690 \mathrm{~cm}^{-1}$. Both results confirm the polymerization was occurred in good manner. Further prepared latex was confirmed by ${ }^{1} \mathrm{H}$ NMR, DSC and TEM.Similarly, fluorinated polymers have been reported to present a wide range of attractive properties especially suitable as non-wettable and weather resistance coating ${ }^{22-23}$.

Liang has prepared fluorinated acrylate by applying emulsion copolymerization cross-linked process ${ }^{24}$. They tried the acrylate base monomer like butyl acrylate (BA) and organo-siloxane with bisacrylate. Their prepared co-polymeric emulsion contains fluorine with the average particle size of 129 to $132 \mathrm{~nm}$ along with small particles. In silk industries for finishing on silk textile containing cross linker agent and without addition of cross-linker agent was attempted. Their result revealed that, treating with the emulsion with or without cross-linker agent, the property of repellence of oil and water of silk fabric extended was found better result with cross linking agent. IR spectra observed stretching vibration of $\mathrm{C}=\mathrm{C}$ at $1643 \mathrm{~cm}^{-1}$ in the molecule of fluoroacrylate was disappeared. It showed that fluorinated polyacrylate latex was formed successfully by emulsion copolymerization. Particle size of latex calculated with the help of SEM and intensity of fluorine signal calculated by NMR spectroscopy ${ }^{25}$.

2,2,3,3,4,4,4-heptafluorobutyl acrylate (HFBA) was successfully synthesized via Reversible Addition Fragmentation Chain Transfer (RAFT) miniemulsion polymerization without using any costabilizer ${ }^{26}$. They have worked for high conversion as well as good colloidal stability,2-cyanopropyl dodecyl trithiocarbonate (CPDTC) with dodecyl group (Z-group) agents were used to prepare 2,2,3,3,4,4,4-heptafluorobutyl acrylate (HFBA) particles through RAFT method. An initiator, potassium per sulphate (KPS) was more appropriate in terms for reaction rate and colloidal stability compared to 2,2'-azo bis isobutyronitrile (AIBN) for initiated the polymerization. RAFT agent provides the control on molecular weights with small PDI was less than 1.2. It was also found that the rate of polymerization was slow with sodium lauryl sulphate (SLS) which was an anionic surfactant than non-ionic surfactant i.e. Triton -X 405. Molar composition of HFBA and BA in the block copolymer was determined by ${ }^{1} \mathrm{H}$ NMR analysis. The ${ }^{1} \mathrm{H}$ NMR spectrum shows the resonances at $4.5 \mathrm{ppm}$ for -O$\mathrm{CH}_{2}-\mathrm{CF}_{2}$ protons of PHFBA segment and 4.0ppm for $-\mathrm{O}-\mathrm{CH}_{2}$ protons of PBA segment. The ratio of the integral area of these resonances shows that the block copolymer has almost $40 \%$ PHFBA. There have been several studies on the surface properties of fluorinated acrylate prepared by conventional fee radical polymerization (FRP) ${ }^{27-30}$.

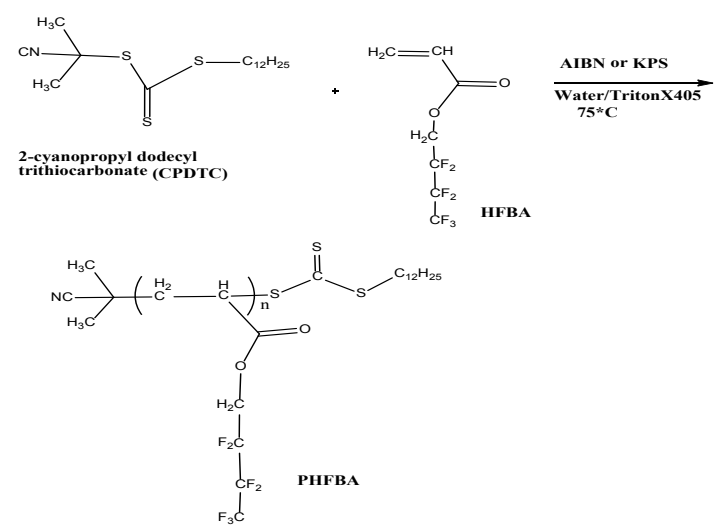

Fig. 1. RAFT Polymerization acrylate HFBA using agent CPDTA

Wei has been enhancing surface properties in the field of fibre, moulding, adhesive and coating, along with fluorine and siloxane components in polymer as surface modification agent ${ }^{31}$. Through two stage emulsion polymerization, fluor silicone acrylic (FSiA) latex has been synthesized, and in this emulsion, two types of core-shell latex particles were present. Fluorinated segment applied at both first and second type sample. Due to unequally distribution of fluorinate segment in both latex particles the glass transmission temperature $\left(T_{g}\right)$ was different in the emulsion. It has been observed that particle size distribution was broad in second type latex particle in comparison to first type. FT-IR spectra of TFEMA, VTES and FSiA copolymer shown the peaks at $1260 \mathrm{~cm}^{-1}$ and $1150 \mathrm{~cm}^{-1}$ were due to stretching vibration $\mathrm{C}-\mathrm{F}$. The characteristic absorption at $760 \mathrm{~cm}^{-1}$ is ascribed to $\mathrm{Si}-\mathrm{CH}_{2}-\mathrm{R}$. Absorptions at $469 \mathrm{~cm}^{-1}$ and $1080 \mathrm{~cm}^{-1}$ belong to asymmetric stretching vibration of $\mathrm{Si}-\mathrm{O}-\mathrm{C}$, while the peak at $957 \mathrm{~cm}^{-1}$ is ascribed to symmetric vibration of Si-O-C. Further samples were characterization by $19 F$ NMR and SEM-EDS technique ${ }^{32-34}$.

Jana have synthesized the fluorine inserted polyacrylate latex via two stage emulsion 
polymerization method ${ }^{35}$. In first stage, fluorinecontaining polyacrylate latexes have been comprised with different levels of copolymerized perfluorethyl groups. Monomers used in this process were 2,2,2-trifluoroethyl methacrylate, methyl methacrylate and butyl acrylate. In second step, fluorineincorporated monomer was copolymerized. Coating wettability, water absorption and water whitening properties of prepared latex were investigated with combination of pre-coalescence, ionomeric crosslinking and keto-hydrazide self-crosslinking. FTIR spectrum confirmed the copolymerization with TFEMA by the appearance of characteristic bands at 1282 and $652 \mathrm{~cm}^{-1}$ that can be assigned to $\mathrm{C}-\mathrm{F}$ stretching and $\mathrm{C}-\mathrm{F}$ wagging, respectively.

Researchers have prepared positively charged fluorinated acrylate copolymer emulsion through semicontinuous seed polymerization process using emulsifier, polysorbate 80 (Tween 80 ) a non-ionic surfactant, Dodecyl trimethylammonium chloride (DTAC) as composite emulsifier and (2-(acryloyloxy) ethyl) trimethylammonium chloride (DMC) as a positively charged monomer ${ }^{36-37}$. Prepared copolymers expressed outstanding adaptability to the cotton fibre and greatly improved the aquaphobic capacity even at low concentration because of strong positive charge on the surface. The prepared latex was used to improve the cotton fabric finishing and cationic surfactant could be a good example for high performance and low-cost finishing agent. The samples containing DFMA monomer displayed the wagging vibration of $C-F$ around $690 \mathrm{~cm}^{-1}$, indicating the presence of PDFMA segment on the copolymers. Cationic fluorinated acrylate copolymers were also successfully confirmed through the ${ }^{1} \mathrm{H}$ NMR, and XPS analyses. All the results manifested the successful polymerization of monomers.

\section{Acrylate Base Latex Films, Its Properties and Characterization}

Steward designed a film of polymer latex which has dramatically increased in these days ${ }^{38}$. Solvent based latex has harmful effect on environment so researchers have to find a substitute. The actual mechanisms involved in deforming spherical particles into void-free films are still the subject of debate. Notwithstanding large vision has been shown with the help of modern instrumental methods like atomic force microscopy, small angle neutron scattering and direct non-radiative energy transfer ${ }^{39-42}$.
Xunhua synthesized alkyl methacrylate ester (AMA) using toluene as inert solvent ${ }^{43}$. Swelling properties of AMA and styrene divinylbenzene ${ }^{44}$, determined in water by calculating the water level of the copolymer with or without methanol pretreatment. Ethylene glycol dimethacrylate (EGDM) used as the crosslinker, the prepared AMA/EGDM copolymers were found that it swelled directly in water rather than their inherent hydrophobic existence. Acrylates which contain lower degree of crosslinking agent, possessed lower swelling behaviour. However, when increasing EGDM portion, the swelling transition was high, and also the water level measured when polymer comes in contact with water for all three types of AMA/EGDM copolymers of monomer like methyl MA (MMA), ethyl MA (EMA), and butyl MA (BMA), attained very large values. When the concentration of crosslinker increases then the swelling of AMA/EGDM copolymers in water was very fast in beginning with high swelling rate order of MMA/EGDM, EMA/EGDM, BMA/EGDM monomers and get swelled, but thereafter it was slow.

The adhesive properties like paste, cut, and peel strength at different compositions shows positive/negative/constant gradients, with same molecular weight distributions of copolymer latex particles of methyl methacrylate and 2-ethyl hexyl acrylate ${ }^{45}$. Effect of paste in the area of low molecular weights was strong when it compared with high molecular weight. There was no effect of the composition on peel strength and shear strength for low-molecular-weight latices; however, there was large enhancement in shear strength for resistance to shear for higher molecular weights. Correlation between the structure of copolymer latex particle, dynamic mechanical properties in solid state copolymer, and peel adhesion performance of the adhesive film were investigated ${ }^{46}$.

Huang studied the small size functional crosslinked poly methyl methacrylate (PMMA) particles of size 1.0 to 5.0 micrometre which were synthesized through dispersion copolymerization in polar medium using Poly(N-vinylpyrrolidone) (PVP) as stabilizer ${ }^{47}$. For initiating this reaction 2,2-azobisisobutyronitrile (AIBN) was used as an initiator and ethylene glycol dimethylacrylate (EGDMA) as cross-linking agent. Effect of concentration of acrylic acid (AA) content in AIBN, EGDMA, and PVP along with medium polarity and 
the reaction temperature were observed. Initially the particle size increased and then decreased with increasing AA concentration in range of 0.7 to 3.5 mol L-1 reached to an extreme of $5.01 \mu \mathrm{m}$ with the concentration of $2.1 \mathrm{~mol}^{\mathrm{L}} \mathrm{L}^{-1}$, while size distribution turns out to be broader.

Stela has been studied interconnected copolymers from acrylamide (AA) and ethyl acrylate ion formed interchangeable product from both primary amine groups with the help of Hofmann degradation of amide groups, or carboxylic groups, prevailed when ester groups come through alkaline hydrolysis process ${ }^{48}$. N, N methylene bisacrylamide divinylbenzene have been used for the purpose of interlinking. After use and without use of crosslinked polymer provided qualitative information about swelling data ${ }^{49-50}$.

\section{Acrylic Polymer Latex Modified with MMA}

In paint industry some water borne polyacrylate with methyl methacrylate (MMA) were used as good binder ${ }^{51-56}$. Butyl acrylate and ethyl acrylate were good examples of acrylate monomer which may be useful in controlling the resin flexibility. In emulsion polymerization method in which surfactant and monomer, which are water soluble and some initiator (APS) which help for initiating the reaction. Monomer composition $\mathrm{P}(\mathrm{MMA} / \mathrm{BA})$ 1:1, $\mathrm{P}(\mathrm{MMA} / \mathrm{MA})$ 1:3, $\mathrm{P}$ (MMA/EA) 1:1.5 gave good result in binding property of acrylate monomers. Finally result showed that after optimization of emulsion polymerization process with regard to emulsifiers, initiator and water-soluble monomers, $\mathrm{P}(\mathrm{MMA} /$ MA) 1:3, P(MMA/EA) 1:1.5 and P(MMA/BA) 1:1. Copolymers were considered to have satisfactory appearance and physical properties to be used as resins in the paint industry. The selected copolymers were found to give neat films.

\section{Batch Emulsion Polymerization MMA-EA-MAA Free Emulsifier Latex}

Through free emulsifier batch emulsion polymerization method, initially seed particles $\mathrm{P}(\mathrm{MMA} / \mathrm{EA})$ of $335 \mathrm{~nm}$ diameter have been prepared $^{57-58}$. Monomer used for functional polymer latex particle along a clean surface and surface with carboxyl group were ethyl acrylate (EA), methyl methacrylate (MMA) and also seed emulsion copolymerization process used for this. Through former polymerization, size along with distribution of functional monomer size in acrylate base latex particle (Dp) have been examined. Using dropping addition method to polymerize, most of monomers gave good result in seed particle latex. Size particle enhanced from $483 \mathrm{~nm}$ to $829 \mathrm{~nm}$ and decreased in ratio of core/shell monomers [C]/[S]. It was observed that when amount of MMA \& initiator increases the size of particle decreased and when amount of MMA decreased and ratio of core/shell increased the particle size remains constant.

Shima has synthesized Acrylonitrilestyrene-acrylate (ASA) structural latexes in a 2-step seeded emulsion polymerization process ${ }^{59}$. In the first-stage, moderately crosslinker i.e. poly (n-butyl acrylate-stat-2-ethyl hexyl acrylate), P (nBAstat2EHA) (75/25 by wt.) and poly (n-butyl acrylate) $(\mathrm{PnBA})$ and rubber cores were obtained. After that in the 2nd step, rubber seed shell was added like a hard poly (styrene-stat-acrylonitrile) (SAN) (70/30 by wt.). Morphology of $2^{\text {nd }}$ step emulsion particle shows that the effect of surfactant and monomer addition in second stage. Non-ionic emulsifier reduced the hydrophilicity of rubber seeds and also affects structures like core shell and raspberry that was depending on addition of monomer. When the mixture of AN/St shell monomer progressively applied to the rubber seed latex, starved-feed condition or semi-batch, then completely opposite rubber core and shell phase were coming out when it compared with actual ASA core shell particles. Finally results revealed the structure of raspberry and core shell interphase layer of ASA composite latex obtained by shell batch emulsion polymerization. Morphology of synthesis latex particle have been studied with controllable size of particle $e^{60-65}$.

\section{Acrylate Latex in Film Coating and Its kinetic Study}

Researchers studied the Co-polymers of methyl methacrylate (MMA) used in coatings in the paint industry, due to its film making ability ${ }^{66-67}$. This ability was due to bond making capacity with other substrate. The adhesion properties coating is very useful for its protection and decoration. Different substrate has different adhesion properties in substrates such as metal, plastic and wood. Monomer like hydroxyl ethyl methacrylate (HEMA butyl acrylate (BuA), 2-ethyl hexyl acrylate (2EHA) were used in process of copolymer of MMA. These monomers improved the roughness, solvent resistance and acid starch properties of substrate. 
For better gel like structure, it is very important to understand the polymerization process and their kinetics. Physical properties of substrate play important role in rate constant. Crosslinker density is one of them on which glass transition temperature depends ( $\mathrm{Tg})$, with an increased interlink density.

Emulsion of equal composition of polyurethane emulsified with with mixture of acrylate base monomers like styrene (St), butyl acrylate (BA) and acrylic acid (AA) were prepared through batch semi emulsion polymerization ${ }^{77}$. Physical property like flexibility/hardness and structure of mix latexes were improved by changing the composition of monomers. It was found that the particle size and flexibility/hardness of PU/AC has been improved in mix-acrylate monomer in hydrous polyurethane dispersion. latex with monomer like MMA, Urethane and combine polyurethane dispersion with other expensive polymer to obtain a cost/performance balance also studied in similar manner ${ }^{78-80}$.

\section{Core-shell Acrylate Base Latexes Prepared via Seeded Polymerization Emulsion method}

A sequence of core-shell acrylate base latexes containing poly (n-butyl acrylate (BA)-comethacrylic acid (MMA)-co-ethylene glycol dimethyl acrylate (EGDMA) as core like monomers and poly (styrene-co-methyl methacrylate) for shell monomer were synthesized via seeded emulsion polymerization technique ${ }^{81-82}$. For eliminate the formation of gel like structure, ethylene glycol dimethyl acrylate used as a crosslinker. It helps to bind core and shell phase with each other. Final result show that core shell ratio achieved at 60:40 with a spherical morphology.

Incorporated of Silver Nanoparticle in Acrylic Latex Silver nanoparticles have been integrated within acrylate monomer like poly methyl methacrylate and butyl acrylate-acrylic acid by two separate processes ${ }^{83}$. In first method nano silver particles dispersed over the acrylate base latex and in the second method silver nanoparticles containing latex, synthesized through miniemulsion polymerization. By miniemulsion polymerization process, diffusion of nano silver in acrylate base latex occur in a better way. Organic particles directly diffused in the monomer droplets that are sum up after polymerization process. Morphological studies of prepared latex were observed through SEM and
TEM techniques. By FTIR and thermal analyses, nanoparticles of silver can be observed in the latex structure. Antibacterial properties of aqueous fullerene nanoparticle $\left(\mathrm{nC}_{60}\right)$ also studied in similar way ${ }^{84}$.

\section{Acrylic Polymer Latex Modified with Stearyl Acrylate}

Amai has investigated the effect of acrylate on adhesion/compatibility of less energy surface for the insertion of acrylate long chain monomer (stearyl acrylate) into polymerization process ${ }^{85}$. They observed that stearyl acrylate affects the elasticity and compatibility of latex but it didn't change the properties of structure ${ }^{86}$.

Christos has prepared two type of copolymers through semi continuous microemulsion copolymerization ${ }^{87}$. In first type of polymers, butyl acrylate (BA), methyl methacrylate (MMA), diacetone acrylamide (DAAM) were used and in $2^{\text {nd }}$ type, monomers like BA/MMA/vinyl neo-decanoate (VeoVa-10)/DAAM were used, ammonium persulfate initiate the above reaction. They have used the redox system to decrease the percentage of free monomer. Some anionic and non-ionic emulsifier used for stabilizing the reaction. Anionic emulsifier was alkylphenol ethoxylates (APEO free) and non-ionic emulsifier was Methacrylic acid (MMA), 2-acrylamido-2-methylpropane sulfonic acid (AMPS), acrylic acid (AA) and various "green". They reported that with changing the percentage of monomer, the properties like particle size, coagulation and water absorption ability was affect ${ }^{88}$.

Similarly, Fabien has been prepared latex of monomer like Lauryl (LA) and stearyl (SA) acrylates through atom transfer radical polymerization method ${ }^{89}$. N,N',N",N"- Pentamethyl diethylenetriamine (PMDETA), used as ligand to control the polymerization process and $\mathrm{CuBr} /$ (PMDETA) acts as suitable catalyst for the preparation of both homopolymers and diblock copolymers of both LA and SA.

\section{Latex Prepared Using Isopropenyl Acetate by Emulsion Polymerization}

Nilesh has synthesized the latex by applying seeded emulsion polymerization using isopropenyl acetate (IPA) as a comonomer ${ }^{90}$. It was observed that by increasing the percentage of IPA into monomer mixture it decreased the copolymerization. Conversion of monomer into 
polymer also affected probably due to IPA which created hindrance. The condition of emulsion quality and size of particle remain same in all condition. Latex of IPA, butyl acrylate, methyl meth acrylate has high glass transition temperature then without IPA latex. Thermal stability reduced when IPA mixed with BA/MMA. That was due to broken of IPA into two stages. When temperature was very high, terpolymer improved its tensile strength.

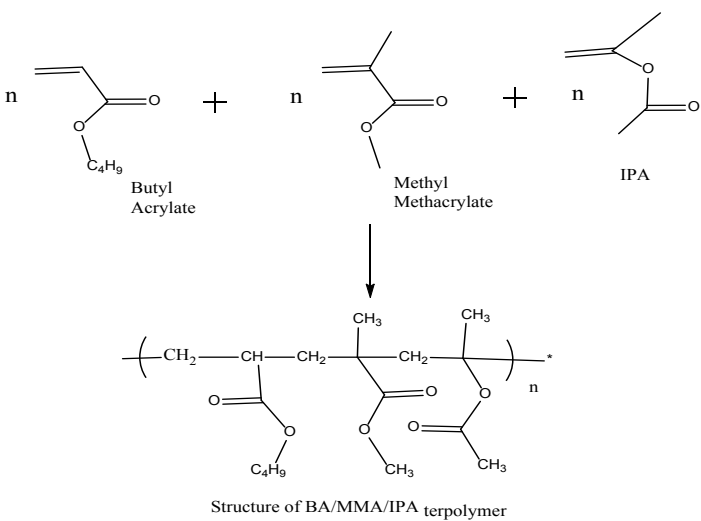

Fig. 2. Structure of BA/MMA/IPA Terpolymer

Acrylic Polymer Latex Modified with GMA-ODA

Atefeh analysed the preparation of linear as well as crosslinked Glycidyl Methacrylate and Octadecyl Acrylate (GMA-ODA) latex, toluene as a solvent through radical copolymerization method ${ }^{91}$. Proton NMR spectroscopy depicts the percentage of monomer in latex. The reactivity of monomer was high in GMA compared to ODA by applying different methods like Mayo-lewis (ML), Fineman-Rose (FR), Inverted Fineman-ross (IFR), Ezrielev-BrokhinaRoskin (EBR), and Kelen-Tudos (KT) methods. It was found that the glass transition temperature ( $\mathrm{Tg})$ value was more than melting temperature of octadecyl groups ( $\mathrm{Tm}$ ) value depicted the enhancement in thermal stability of prepared latex.
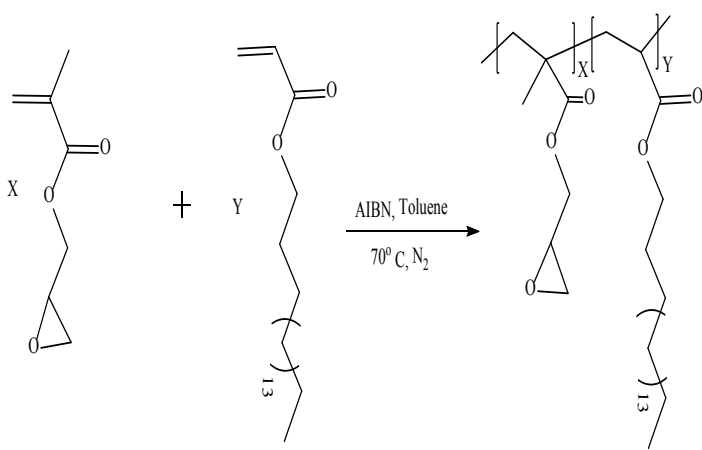

Fig. 3. Radical copolymerization of GMA and ODA
It was observed that when percentage of GMA was high then swelling ration increased in polar solvent. In the meantime, affinity had high in toluene with compared to benzene and crude oil. In crosslinked latex when insert of GMA then absorption property reduced when the solvent was nonpolar organic.

\section{Nanocomposite Latex Using Silica with Styrene and Butyl Acrylate}

Nanocomposite latexes of acrylate monomer like butyl acrylate with silica (methacryloxy propyl trimethoxy) and styrene were prepared via situ emulsion polymerization method ${ }^{92}$. Prepared latex has mononuclear core-shell structure in which nanoparticle of silica was core and polyacrylate as a shell material. Result showed that when silica nanoparticles were added in latex, the intensity of silane modification of silica nanoparticles was affected along $\mathrm{pH}$ of reaction especially within $\mathrm{pH}$ range from 3 to 4.5. Mechanical properties of latex were enhanced with insertion of silica nanoparticles due to strong interaction between silica surface and hydroxy group.

$\mathrm{M}$ has been prepared latex with acrylate monomer like ethyl acrylate and methyl acrylate with the help of batch reactor through emulsion polymerization ${ }^{93}$. Various latexes have been prepared with different compositions of monomer. It was found that reaction was temperature dependant and the optimum temperature was $60^{\circ} \mathrm{C}$, above this temperature the reaction was highly exothermic. The entire prepared lattice showed high dispersity measured by quasi-elastic light scattering (QELS) and characterized via electron transmission microscopy (ETM).

Cuifeng Zhang has prepared the polyacrylate latex containing fluorine and silicon by semi-continuous seeded emulsion polymerization in the presence of the mixed emulsifier of novel sodium lauroyl glutamate (SLG) anion surfactant and BCE-10 non-ionic surfactant, which methyl methacrylate (MMA) and butyl acrylate (BA) were used as main monomers and hexafluorobutyl methacrylate (HFMA) and vinyltriethoxysilane (VTES) were used as the functional monomers ${ }^{94}$. Optimal condition determined of emulsion by mixing different ratio of emulsifier. characterization of prepared latex observed by FTIR, DSC, and thermogravimetric analysis. 


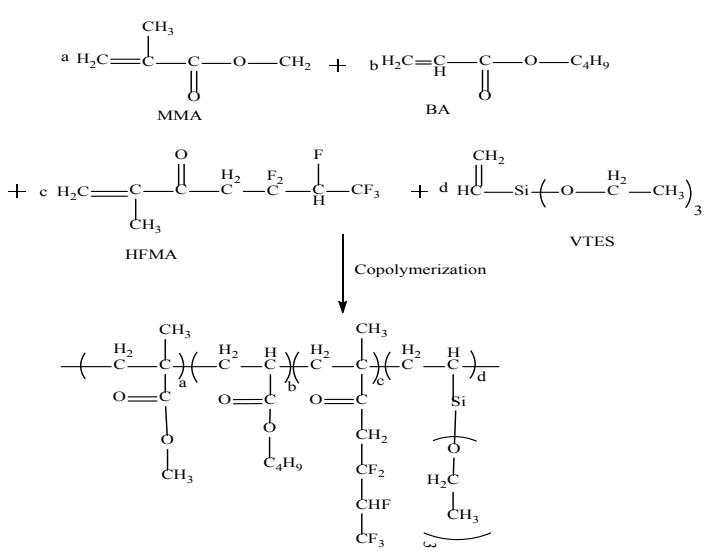

Fig. 4. Novel acrylate latex containing fluorine and silicon

Polymer latex of stearyl acrylate (SA) was prepared through two step mini-emulsion polymerization technique. In first step, SA was inserted for controlling the degree of crystallinaty in homopolymerisation. In $2^{\text {nd }}$ step, short chain of monomer like butyl acrylate, methyl acrylate and acrylic acid were mixed. With increasing the concentration of stearyl acrylate in polymerization, the magnitude of $2^{\text {nd }}$ phase decreased and found some secondary nuclei existed ${ }^{95}$.

\section{Insertion of Nanocomposites in Acrylate Latex}

Angel has prepared the nano composites of waterborne acrylate/ $\mathrm{SiO}_{2}$ nanocomposite through emulsion polymerization using batch process ${ }^{96}$. The exitance of nano silica particles with size of $7 \mathrm{~nm}$ were recorded in synthesized emulsion-latex of polymethyl methacrylate (PMMA), acrylic acid (AA) and butyl acrylate (BA). Optimum insertion of silica nano particles was upto $3.0 \% \mathrm{~g} / \mathrm{g}$ in prepared acrylate latex. It was found that the increasing concentration of nano silica led to decrease in degree of conversion rate and slight increase in value of coagulum. Continuous decrease in the amount of nano silica particles then size of latex particle reaches a constant value of $150 \mathrm{~nm}$.

Situ emulsion polymerization is an effective way for the copolymerization of acrylate polymers such as poly (butyl acrylate-co-methyl acrylate) with cellulose nanocrystals (CNCs) which were separated from cotton, wood pulp and other organic sources ${ }^{97-98}$. CNCs are easily accessible and nontoxic compounds. Improvement in properties like glass transition temperature $(\mathrm{Tg})$, viscosity loss moduli of latex and particle size were also observed due to CNCs being in latex.

\section{Acrylic Polymer Latex Modified with Mixed Surfactant}

Lijun took surfactant like alkyl Polyglycoside (APG1214) with disodium laureth sulfosuccinate (MES) to synthesized polyacrylate latex through seeded semi continuous polymerization ${ }^{99}$. $7.0 \%$ emulsifier, 3:1 mass ratio of APG1214 to MES, $0.7 \% \mathrm{KPS}$, equal mass ratio of MMA to $\mathrm{BA}$ and $2.0 \%$ of $A A$ were optimum concentration for polymer acrylate latex. Acrylate base monomers like methyl methacrylate (MMA) and Butyl acrylate (BA) along with potassium per sulphate (KPS) as initiator were used in synthesis. Result showed that the conversion of monomer into latex was fast which enhance the ionic as well as mechanical stability of latex.

Sweta has studied the hardness, compatibility, flexibility and lustre of polymer films using American society of testing and methods (ASTM) standard ${ }^{100}$. These physical properties were varied with change in molar ratio of monomers during polymerisation. The films had good flexibility with the higher content of butyl acrylate (BA) or ethyl hexyl acrylate (EHA) in the feed whereas gloss decreased. The acceptability of latexes for coating applications was ascertained by comparing their physical properties. It was recognized that the copolymer latexes synthesized with 7:3 to $6: 4$ of MMA to BA molar ratios had more compatible for their use in coatings. While in case of MMA: EHA copolymers the suitable molar ratios for coating application were 8:2 to $7: 3$.

Lijun has studied the application of homopolymers as well as copolymers of octadecyl acrylate and styrene synthesized at varying conditions like temperature/time/molar ratios of monomers, as viscosity reducers for heavy oil and compared it with ethyl acrylate latex ${ }^{101}$. The prepared latex gave better performance in viscosity reduction of heavy oil as compared to existed methods like heating and emulsification.

Dawei has studied the copolymer of large side chain acrylate base monomer (SA) with other monomer like methyl meth acrylate/ethyl acrylate which were synthesized via emulsion polymerization method. In this reaction sodium lauryl sulphate acts as emulsifier and potassium per sulphate as initiator. Prepared latex improved the hydrophobicity of latex film ${ }^{102}$. 


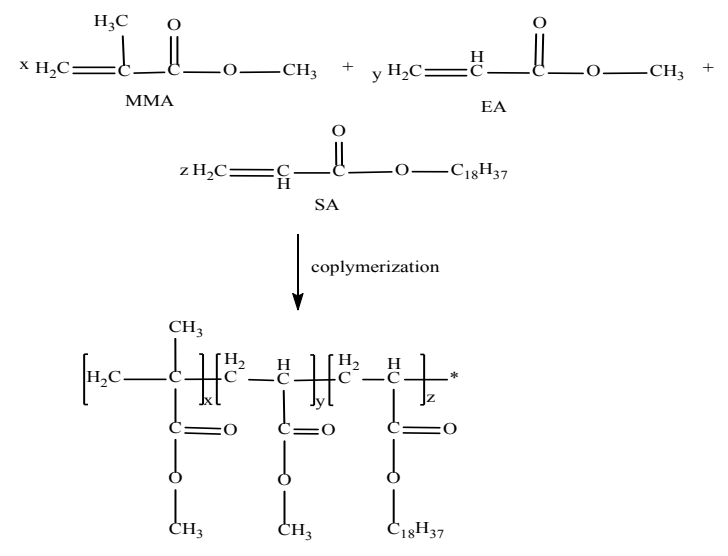

Fig. 5. Polyacrylate

Preparation of Superparamagnetic Composite Latex by Pickering Miniemulsion Polymerization

Mj has synthesized superparamagnetic $\mathrm{Fe}_{2} \mathrm{O}_{3} @ \mathrm{LS} @ \mathrm{PS}$ composite latex particles from $\mathrm{Y}-\mathrm{Fe}_{2} \mathrm{O}_{3}$ magnetic nanoparticles (MNPs) by Pickering miniemulsion polymerization process. Prepared nanoparticles and latex particles were characterized and confirmed by TEM, UV-spectra, XRD, Raman spectra and optical microscopy ${ }^{103}$. LS-modified MNPs was used as stabilizer and nanoparticle of MNPs also used the stability of polymerization of styrene droplet. LS particle worked as a bridge because its show both hydrophobic and hydrophilic part. Its structure on the surface of latex looked like strawberry type. Due to charge neutralization capacity it was used as modifier in inorganic particle and could destroy stability of composite. It has very low cost and having properties like eco-friendly, sustainability, renewable and so used as best modifier in inorganic particle.

Sadaf has done the reaction in Pyrex glass reactor equipped with a water bath, mechanical stirrer, $\mathrm{N}_{2}$ atmosphere, thermocouple, condenser, pressure equalizer for reacting monomers like polystyrene and acrylate monomer like 2-ethylhexyl acrylate with insertion of clay or silicate layered through emulsion polymerization technique. For synthesis of latex nanocomposite polymer, ammonium persulphate added as initiator, buffer solution of sodium carbonate added to neutralize the heel and $\mathrm{NH}_{4} \mathrm{OH}$ solution control the $\mathrm{pH}$ range 7.0-9.0 of reaction mixture ${ }^{104}$. Interlayer d-spacing of prepared latex composite was increased from $1.87 \mathrm{~nm}$ (nano clay) to $2.52 \mathrm{~nm}$ in one of their sample. Glass transition $(\mathrm{Tg})$ temperature of composite was increased which enhanced the thermal stability of latex composite but in lower content of nanoclay, thermal stability decreased, probably due to changing the degree of exfoliation structure and forming the intercalated structure of nanoclay into the polymer, SEM and TEM of samples confirmed. Luis has worked to study the effects of change in the percentage of Trimethylindium (TMI) from $0-6 \%$ in acrylate base latex which improved some properties like flexibility, tensile strength as well as hardness of film. Prepared latex with promoter TMI behaved like binder in water-based paint industry for coating the materials of steel component. Their study explored the improvement in elongation, hardness, fatigue limit, and tensile strength of prepared latex ${ }^{105}$. It was observed that $2-4 \% \mathrm{TMI}$ gave better result as a binder in paint industry and its coating improved the adhesion on steel specimens, which also increased gloss and hardness property.

Dankova has prepared two latex binders of Zinc oxide nanoparticles (NPsZno) by semicontinuous emulsion polymerization method using different concentration of acrylic monomers (MMA, BA, diacetone acrylamide DAAM) with crosslinker as adipic acid dihydrazide and APS as initiator. They studied the properties of new nanoparticle of zinc oxide (NPsZno), self-crossing latexes as a paint binder which improved resistivity, tensile strength, hardness, anticorrosion, antimicrobial, compatibility with compared to existed latex ${ }^{106-107}$.

Acrylate base of stearyl acrylate and glycidyl methacrylate has been synthesized through atom transfer radical copolymerization technique in presence of copper(I) bromide with tris[(2-pyridyl)-methyl]-amine as catalyst and ethyl 2-bromoisobutyrate initiator ${ }^{108-109}$. Prepared latex gave better result for improving thermal property to control temperature. It is also used in diesel for thermal oxidation resistance and environment friendly capability.

\section{Concentration Effect Emulsifier like Sodium Lauryl Sulphate (SLS) in Acrylic Latex}

Eren has investigated the concentration effect of sodium lauryl sulphate (SLS) emulsifier in copolymerization of styrene/acrylic acid/butyl acrylate copolymer (SAC) latex particles synthesized through seeded emulsion polymerization technique. Scanning electron microscopy (SEM), minimum filmforming temperature (MFFT), differential scanning 
calorimetry (DSC), dynamic light scattering (DLS), thermo gravimetric analysis (TGA) techniques were studied to observe the change on physicochemical properties and morphology ${ }^{110-111}$. The focus of their research was to determine an excellent surfactant concentration to obtain latexes with low MFFT. DLS studies showed that the particle size decreases 118.30 to $75.18 \mathrm{~nm}$ with the increase of SLS concentration. MFFT of latexes decreased with increasing SLS concentration. From the TGA curves, it was found that all the SAC latex particles exhibit a three-step decomposition process. The observed single glass transition temperature $(\mathrm{Tg})$ values for SAC particles showed that the latexes were prepared successfully ${ }^{112-115 .}$

Shukla has synthesized acrylate base latex of methyl methacrylate (MMA), butyl methacrylate (BMA) in which poly (propylene glycol diacrylate) PPGDA acts as crosslinker. Their research explored the effect of added PPGDA in different proportions during latex synthesis ${ }^{116}$. Latex was characterized by FTIR, SEM and differential scanning calorimetry DSC studies. It was found that PPGDA inserted latex was better binder than simple latex.

\section{Theoretical and Practical Understanding of Emulsion Polymerization}

Petter gave a detailed review about basics of polymerization emulsion techniques. This review article provides some benefit information about theoretically and practical properties of latex for researcher. It also provides some important application of acrylate base latex ${ }^{117-121}$.

Chen has synthesized the cationic polyacrylate latexes series through semi-continuous seeded emulsion polymerization from methyl meth acrylate (MMA) and butyl acrylate (BA) monomers and 2,2'-azobis[2-(2-imidazolin-2-yl)-propane] dihydrochloride (AIBI) used in small amount as a cationic comonomer ${ }^{122-123}$. AIBI composition in latex affected the absorption rate, coagulation, and water absorption properties ${ }^{124-129}$.

\section{Thermal properties of Polyacrylate}

Thermal stability of polymeric materials is an important physical property which is required for many applications. These properties may be profoundly affected by the presence of particular sequences of comonomers as well as with quite small proportions of additives. Thermal properties of polymeric material have been studied with the help of Thermogravimetric technique (TGA) and Differential scanning calorimetry (DSC). Thorough study of the thermal curves so obtained revealed that the characteristics of the curves of the compound resulting from the cooperative interactions are different from those of the constituent polymers. The differences in the characteristics of the thermal curves were attributed to the formation of a polyacrylate complex resulting from the interaction of monomers. The DSC studies showed endothermic peaks where condensation reaction took place and exothermic peaks pointing toward the possibility of crosslinking reactions. The TGA studies showed weight loss percentage of polyacrylate compound at different temperatures ${ }^{130-140}$.

J.M. Cervantes-Uc et al., studied the thermal degradation temperature of polymethacrylates containing carboxylic groups namely poly (methacryloyloxy butanoic acid). PMBA poly (methacryloyloxy hexanoic acid), PMHA and poly ( $p$-methacryloyloxy benzoic acid), PMBeA was investigated by TGA/FTIR. By TGA it was observed that PMBA exhibited two well-defined degradation stages at 327 and $450^{\circ} \mathrm{C}$. O. R. Pardini et al., showed that the thermal degradation temperature of Polyurethane (PU) polymer was at $550^{\circ} \mathrm{C}$. M. A. Moharram et al., synthesized the polyacrylate of poly (acrylic acid) PAA and poly(acrylamide) PAAm and it was stable at temperature $650^{\circ} \mathrm{C}$. S.K Mukhopadhyay et al., showed the thermal results of vinyl acetate-2-Ethylhexyl acrylate copolymer (VAc-EHA) at temperature $548^{\circ} \mathrm{C}$. M.Leskovac et al was investigated Thermal stability of poly (methy1 methacrylate-co-butyl acrylate) and poly (styreneco-butyl acrylate) modified with a small amount of acrylic acid and/or $\mathrm{N}$-methylolacrylamide as a crosslinking agent. The decomposition temperature of synthesized polyacrylate was $388^{\circ} \mathrm{C}$. C.McNeill et al studied the thermal degradation behaviour of Styrene-methacrylic acid copolymer. Thermal degradation temperature range of prepared copolymer was $400-480^{\circ} \mathrm{C}$.

\section{CONCLUSION}

Acrylic polymer latex plays key role in recent academics and industrial use like paint, concrete composites, surface coating, synthetic 
rubber, paper industry, adhesives, textile, and many other products. In this article our main emphasis is to highlight the synthesis techniques (Batch emulsion, Seeded emulsion, Situ miniemulsion, Atom transfer radical, Free radical copolymerization, Pickering miniemulsion, Semi-continuous seeded emulsion, dispersion copolymerization, aqueous suspension polymerization) of various acrylics-based polymer latex using monomers such as MMA, EA,BA, acrylonitrile styrene, polyurethane, lauryl stearyl, including initiators like APS, KPS, crosslinkers, nanocomposites and others materials. Prepared latexes were characterized by IR peak at 1640 $\mathrm{cm}^{-1}$ due to $\mathrm{C}=\mathrm{C}$ of monomers, was disappeared in polymer latex, SEM \& TEM shows the increase in size of particles in latex from $\sim 1.8 \mathrm{~nm}-\sim 2.52 \mathrm{~nm}$, $\mathrm{XRD}, \mathrm{TGA} / \mathrm{DSC}$ curves represents the increase in decomposition temperature $\sim 400$ oC for latex etc. It was observed that $2-4 \% \mathrm{TMI}$ gave better result as a binder in paint industry and its coating improved the adhesion on steel specimens. Nanoparticle of zinc oxide (NPsZno), self-crossing latexes as a paint binder which improved resistivity, tensile strength, hardness, anticorrosion, antimicrobial, compatibility with compared to existed latex. Acrylate base of stearyl acrylate and glycidyl methacrylate may be used in diesel for thermal oxidation resistance and its environment friendly capability. Researchers have to work for the possibilities in latex/modified latex of possessing improved properties like thermal stability, mechanical strength, durability, chemical resistance, viscosity reducer for heavy oils, and additionally their ease of processing as a substitute of traditionally synthesized polymer latex.

\section{ACKNOWLEDGEMENT}

Gratitude to acknowledges the financial assistance provided by Human Resource Development Group (HRDG) Council of Scientific \& Industrial Research (CSIR), New Delhi, India to carry out this work under reference no. [09/105(0285/2018 EMR-I)].

\section{Conflict of interest}

The authors declared no conflict of interest.

\section{REFERENCES}

1. Capek, I.; Barton, J.; Orolinova, E., Chem. Zvesti., 1984, 38 (6), 803-822.

2. Malshe, V.; Sangaj, N. S., Progress in Organic Coatings., 2005, 53 (3), 207-211.

3. Landfester, K.; Rothe, R.; Antonietti, M., Macromolecules 2002, 35 (5), 1658-1662.

4. Urquiola, B.; Arzamendi, G.; Leiza, J. R.; Zamora, A.; Asua, J. M.; Delgado, J.; ElAasser, M. S.; Vanderhoff, J. W., Journal of Polymer Science Part A: Polymer Chemistry., 1991, 29 (2), 169-186.

5. Sasseville, D., Acrylates. Dermatitis., 2012, $23(1), 3-5$.

6. Briggs, P.; Jialanella, G., Advances in structural adhesive bonding., 2010, 132-150.

7. Ballard, N.; Hamzehlou, S.; Asua, J. M., Macromolecules., 2016, 49 (15), 5418-5426.

8. Barnes, C. E., Journal of the American Chemical Society., 1945, 67 (2), 217-220.

9. Slomkowski, S.; Alemán, J. V.; Gilbert, R. G.; Hess, M.; Horie, K.; Jones, R. G.; Kubisa, P.; Meisel, I.; Mormann, W.; Penczek, S., Pure and Applied Chemistry., 2011, 83 (12), 2229-2259.

10. Vandenbergh, J.; Junkers, T.; Olabisi, O.;
Adewale, K., Handbook of Thermoplastics., 2016, 2.

11. Rehberg, C.; Fisher, C., Chemical Society., 1944, 66 (7), 1203-1207.

12. Ajekwene, K. K., Acrylate Polymers for Advanced Applications., 2020, 35.

13. Zahran, M. A.; Abd El-Mawgood, W. A.; Basuni, M. M., KGK-KAUTSCHUK GUMMI KUNSTSTOFFE., 2016, 69 (7-8), 53-58.

14. Barner-Kowollik, C., Wiley Online Library: 2009.

15. Yu, M.; Zhang, B.; Deng, B.; Yang, X.; Sheng, K.; Xie, L.; Lu, X.; Li, J., Journal of applied polymer science., 2010, 117 (6), 3575-3581.

16. Soer, W. J.; Ming, W.; Koning, C. E.; van Benthem, R. A., Polymer., 2008, 49 (16), 3399-3412.

17. Chen, Y.; Zhang, C.; Wang, Y.; Cheng, S.; Chen, P., Journal of Applied Polymer Science., 2003, 90 (13), 3609-3616.

18. Han, D.; Zhu, L.; Chen, Y.; Li, W.; Feng, L., Journal of Fluorine Chemistry., 2013, 156, 38-44.

19. Xiao, X.; Wang, Y., Colloids and Surfaces A: Physicochemical and Engineering Aspects., 2009, 348 (1-3), 151-156. 
20. Bouvier-Fontes, L.; Pirri, R.; Asua, J. M.; Leiza, J. R., Macromolecules., 2005, 38 (4), 1164-1171.

21. He, L.; Liang, J.; Zhao, X.; Li, W.; Luo, H., Progress in Organic Coatings., 2010, 69 (4), 352-358.

22. Appelhans, D.; Wang, Z.-G.; Zschoche, S.; Zhuang, R.-C.; Häussler, L.; Friedel, P.; Simon, F.; Jehnichen, D.; Grundke, K.; Eichhorn, K.-J., Macromolecules., 2005, 38 (5), 1655-1664.

23. Lazzari, M.; Aglietto, M.; Castelvetro, V.; Chiantore, O., Chemistry of materials., 2001, 13 (9), 2843-2849.

24. Shan, L.; Li, Z. X.; Xu, Y.; Cai, L.; Zang, X.; Wu, L. Advanced Materials Research, Trans Tech Publ., 2013, 360-363.

25. Tang, X.; Shen, Y.-D., e-Polymers., 2010, 10(1).

26. Chakrabarty, A.; Singha, N. K., Journal of colloid and interface science., 2013, 408, 66-74.

27. Park, I. J.; Lee, S.-B.; Choi, C. K.; Kim, K.-J., Journal of colloid and interface science.,1996, 181 (1), 284-288.

28. Sheiko, S.; Lermann, E.; Möller, M., Langmuir., 1996, 12 (16), 4015-4024.

29. Timperley, C. M.; Arbon, R. E.; Bird, M.; Brewer, S. A.; Parry, M. W.; Sellers, D. J.; Willis, C. R., Journal of Fluorine Chemistry., 2003, 121 (1), 23-31.

30. Tsibouklis, J.; Graham, P.; Eaton, P. J.; Smith, J. R.; Nevell, T. G.; Smart, J. D.; Ewen, R. J., Macromolecules., 2000, 33 (22), 8460-8465.

31. Yang, W.; Zhu, L.; Chen, Y., Journal of Fluorine Chemistry., 2015, 170, 17-23.

32. Guan, C.-M.; Luo, Z.-H.; Qiu, J.-J.; Tang, P.P., European polymer journal., 2010, 46 (7), 1582-1593.

33. lyengar, D. R.; Perutz, S. M.; Dai, C.-A.; Ober, C. K.; Kramer, E. J., Macromolecules., 1996, 29 (4), 1229-1234.

34. Shirahama, H.; Suzawa, T., Journal of applied polymer science., 1984, 29 (12), 3651-3661.

35. Machotová, J.; Černošková, E.; Honzíček, J.; Šňupárek, J., Progress in Organic Coatings., 2018, 120, 266-273.

36. Chen, Y.; Fu, F.; Yang, G.; Liu, Y.; Lv, Y.; Liu, M., Journal of Coatings Technology and
Research., 2020, 17 (4), 875-885.

37. Tan, J.; Liu, W.; Wang, H.; Sun, Y.; Wang, S., Progress in Organic Coatings., 2016, 94, 62-72.

38. Steward, P.; Hearn, J.; Wilkinson, M., Advances in colloid and interface science., 2000, 86 (3), 195-267.

39. Charmeau, J.; Kientz, E.; Holl, Y., Progress in organic coatings., 1996, 27 (1-4), 87-93.

40. Keddie, J. L., Materials Science and Engineering: R: Reports., 1997, 21 (3), 101-170.

41. Sheetz, D., Journal of Applied Polymer Science., 1965, 9 (11), 3759-3773.

42. Chainey, M.; Wilkinson, M.; Hearn, J., Journal of applied polymer science., 1985, 30 (11), 4273-4285.

43. Wang, X.; Yan, J.; Zhou, C., Journal of applied polymer science., 2000, 78 (2), 250-258.

44. Yan, J.; Wang, X.; Chen, J., Journal of applied polymer science., 2000, 75 (4), 536-544.

45. Laureau, C.; Vicente, M.; Barandiaran, M.; Leiza, J.; Asua, J., Journal of applied polymer science., 2001, 81 (5), 1258-1265.

46. Mayer, A.; Pith, T.; Hu, G. h.; Lambla, M., Journal of Polymer Science Part B: Polymer Physics., 1995, 33 (12), 1781-1791.

47. Huang, J. X.; Yuan, X. Y.; Yu, X. L.; Zhang, H. T., Polymer international., 2003, 52 (5), 819-826.

48. Dragan, S.; Dinu, M. V.; Vlad, C. D., Journal of applied polymer science., 2003, 89 (10), 2701-2707.

49. Dragan, E.; Avram, E.; Dinu, M., Polymers for advanced technologies., 2006, 17 (7-8), 571-578.

50. Tanaka, H.; Senju, R., Bulletin of the chemical society of Japan., 1976, 49 (10), 2821-2823.

51. Tığlı, R. S.; Evren, V., Progress in Organic Coatings., 2005, 52 (2), 144-150.

52. Weiss, K. D., Paint and coatings: Progress in polymer science., 1997, 22 (2), 203-245.

53. Yeum, J.-H.; Deng, Y., colloid and polymer science., 2005, 283 (11), 1172-1179.

54. Soldi, R. A.; Oliveira, A. R.; Barbosa, R. V.; César-Oliveira, M. A., European Polymer Journal., 2007, 43 (8), 3671-3678.

55. Pawar, E., IOSR J. Mech. Civ. Eng., 2016, 13 (2), 1-4. 
56. Mignon, A.; Devisscher, D.; Graulus, G.J.; Stubbe, B.; Martins, J.; Dubruel, P.; De Belie, N.; Van Vlierberghe, S., Carbohydrate polymers., 2017, 155, 448-455.

57. Kang, K.; Kan, C.; Du, Y.; Liu, D., European polymer journal., 2005, 41 (3), 439-445.

58. Aslamazova, T., Progress in organic coatings., 1995, 25 (2), 109-167.

59. Tolue, S.; Moghbeli, M. R.; Ghafelebashi, S. M., European Polymer Journal., 2009, 45 (3), 714-720.

60. Misra, S.; Pichot, C.; El-Aasser, M.; Vanderhoff, J., Journal of Polymer Science: Polymer Letters Edition., 1979, 17 (9), 567-572.

61. Pichot, C.; Llauro, M. F.; Pham, Q. T., Journal of Polymer Science: Polymer Chemistry Edition., 1981, 19 (10), 2619-2633.

62. Herrera, V.; Pirri, R.; Asua, J. M.; Leiza, J. R., Journal of Polymer Science Part A: Polymer Chemistry., 2007, 45 (12), 2484-2493.

63. Moghbeli, M.; Mohammadi, N.; Bagheri, R., Synthesis of SBR/PMMA core/shell latices: Journal of applied polymer science., 2007, 105 (3), 1412-1419.

64. Grancio, M.; Williams, D., Journal of Polymer Science Part A-1: Polymer Chemistry., 1970, 8 (9), 2617-2629.

65. Winnik, M. A.; Zhao, C. L.; Shaffer, O.; Shivers, R. R., Langmuir., 1993, 9 (8), 2053-2065.

66. Srivastava, S., Designed monomers and polymers., 2009, 12 (1), 1-18.

67. Lee, C. F.; Lin, K. R.; Chiu, W. Y., Journal of applied polymer science., 1994, 51 (9), 1621-1628.

68. Lee, C. F.; Chiu, W. Y., Journal of applied polymer science., 1995, 56 (10), 1263-1274.

69. Liang, K.; Hutchinson, R. A., Macromolecules., 2010, 43 (15), 6311-6320.

70. Mwaura, J.; Mathai, M.; Chena, C.; Papadimitrakopoulosa, F., Journal of Macromolecular Science, Part A: Pure and Applied Chemistry., 2006.

71. Scott, G.; Senogles, E., Kinetic relationships in radical polymerization., 1973.

72. Wang, W.; Hutchinson, R. A., AIChE journal., 2011, 57 (1), 227-238.

73. Junkers, T.; Schneider-Baumann, M.; Koo, S. S.; Castignolles, P.; Barner-Kowollik, C.,
Macromolecules., 2010, 43 (24), 10427 10434.

74. Plessis, C.; Arzamendi, G.; Leiza, J. R.; Schoonbrood, H. A.; Charmot, D.; Asua, J. M., Macromolecules., 2001, 34 (15), 5147-5157.

75. Nikitin, A. N.; Hutchinson, R. A., Macromolecules., 2005, 38 (5), 1581-1590.

76. Yamada, B.; Azukizawa, M.; Yamazoe, H.; Hill, D.; Pomery, P., Polymer., 2000, 41 (15), 5611-5618.

77. Athawale, V. D.; Kulkarni, M. A., Progress in Organic Coatings., 2009, 65 (3), 392-400.

78. Wu, L.; You, B.; Li, D., Journal of applied polymer science., 2002, 84 (8), 1620-1628.

79. Tsavalas, J. G. Georgia Institute of Technology., 1998.

80. Song, C.; Yuan, Q.; Wang, D., Effect of the content of urea groups on the particle size in water-borne polyurethane or polyurethane/ polyacrylate dispersions. Colloid and Polymer Science., 2004, 282 (6), 642-645.

81. Borthakur, L. J.; Jana, T.; Dolui, S., Journal of coatings technology and research., 2010, 7 (6), 765-772.

82. Cheng, S.; Chen, Y.; Chen, Z., Journal of applied polymer science., 2002, 85 (6), 1147-1153.

83. Mamaghani, M. Y.; Pishvaei, M.; Kaffashi, B., Macromolecular Research., 2011, 19 (3), 243-249.

84. Brunet, L.; Lyon, D. Y.; Hotze, E. M.; Alvarez, P. J.; Wiesner, M. R., Environmental science \& technology., 2009, 43 (12), 4355-4360.

85. Agirre, A.; Nase, J.; Degrandi, E.; Creton, C.; Asua, J. M., Journal of Polymer Science Part A: Polymer Chemistry., 2010, 48 (22), 5030-5039.

86. Toyama, M.; Ito, T.; Nukatsuka, H.; Ikeda, M., Journal of Applied Polymer Science., 1973, 17 (11), 3495-3502.

87. Koukiotis, C.; Sideridou, I. D., Progress in Organic Coatings., 2010, 69 (4), 504-509.

88. Guo, T. Y.; Liu, J. C.; Song, M. D.; Zhang, B. H., Journal of applied polymer science., 2007, 104 (6), 3948-3953.

89. Dutertre, F.; Pennarun, P.-Y.; Colombani, O.; Nicol, E., European polymer journal., 2011, 47 (3), 343-351. 
90. Shinde, N.; Kathalewar, M.; Sabnis, A., International Journal of Industrial Chemistry., 2012, 3 (1), 1-8.

91. Darvishi, A.; Zohuriaan Mehr, M. J.; Marandi, G. B.; Kabiri, K.; Bouhendi, H.;Bakhshi, H., Designed Monomers and Polymers., 2013, 16 (1), 79-88.

92. Hashemi-Nasab, R.; Mirabedini, S., Progress in Organic Coatings., 2013, 76 (7-8), 1016-1023.

93. Corea, M.; Lo' pez-Castan $\sim$ ares, R.; Brunner, P.-L.; Va' zquez, F.; Olivares, M., International Journal of Polymeric Materials., 2005, 54 (5), 347-357.

94. Zhang, C.; Xu, T.; Bao, Z.; Fu, Z.; Chen, L., Journal of adhesion science and Technology., 2017, 31 (15), 1658-1670.

95. Mehravar, E.; Leiza, J. R.; Asua, J. M., Polymer., 2016, 84, 167-177.

96. Romo-Uribe, A.; Arcos-Casarrubias, J. A.; Hernandez-Vargas, M. L.; Reyes-Mayer, A.; Aguilar-Franco, M.; Bagdhachi, J., Progress in Organic Coatings., 2016, 97, 288-300.

97. Dastjerdi, Z.; Cranston, E. D.; Dubé, M. A., Macromolecular Reaction Engineering., 2017, 11 (6), 1700013.

98. Perrin, F. X.; Nguyen, V. N.; Vernet, J. L., Polymer international., 2002, 51 (10), 1013-1022.

99. Chen, L.; Shao, T.; Zhang, X.; Wang, X.; Chen, D., Polymers from Renewable Resources., 2018, 9 (3-4), 145-151.

100. Shukla, S.; Rai, J., World Scientific News., 2018, 113, 78-86.

101. Zhu, L.; Wang, S.; Huang, C.; Tian, Y.; Yang, X.; Jing, X.; Li, A. IOP Conference Series: Earth and Environmental Science, IOP Publishing., 2018, 022032.

102. Chen, D.; Chen, L., Journal of Macromolecular Science, Part A., 2020, 57 (4), 250-255.

103. Zhou, M.; Zhou, S.; Pang, X.; Li, K.; Qiao, X., Colloids and Surfaces A: Physicochemical and Engineering Aspects., 2020, 585, 124040.

104. Kazemi, S.; Mirzamohammadi, S.; Akbarzadeh, A.; Ebrahimnezhad-Khaljiri, H., Silicon., 2021, 13, 831-840.

105. Elizalde, L. E.; Mendoza, J. J.; LedezmaRodríguez, R.; Treviño, M. E.; Mondragon, M., Journal of Coatings Technology and Research 2020.

106. Danková, M.; Kalendová, A.; Machotová,
J., Journal of Coatings Technology and Research., 2020, 17 (2), 517-529.

107. Delibaş, A., Journal of Coatings Technology and Research., 2021, 18 (3), 717-727.

108. Pavlovskaya, M.; Kriulichev, I.; Grishin, D., Russian Journal of Applied Chemistry., 2020, 93 (9), 1332-1339.

109. Coessens, V.; Pintauer, T.; Matyjaszewski, K., Progress in polymer science., 2001, 26 (3), 337-377.

110. Bilge, E.; SOLMAZ, Y., Sakarya Üniversitesi Fen Bilimleri Enstitüsü Dergisi., 2020, 24 (5), 1076-1082.

111. Yu-Su, S. Y.; Sun, F. C.; Sheiko, S. S.; Konkolewicz, D.; Lee, H.-i.; Matyjaszewski, K., Macromolecules., 2011, 44 (15), 5928-5936.

112. Capek, I.; Bartoň, J.; Tuan, L. Q.; Svoboda, V.; Novotnýa, V.,. Macromolecular Chemistry and Physics., 1987, 188 (7), 1723-1733.

113. Aramendia, E.; Mallégol, J.; Jeynes, C.; Barandiaran, M. J.; Keddie, J. L.; Asua, J. M., Langmuir., 2003, 19 (8), 3212-3221.

114. Pham, V. H.; Lee, Y. H.; Lee, D. J.; Chung, J. S., Korean journal of chemical engineering ., 2009, 26 (6), 1585-1590.

115. Vijayendran, B.; Bone, T.; Sawyer, L., Journal of Dispersion Science and Technology., 1982, 3 (1), 81-97.

116. Shukla, S., High Performance Polymers., 2020, 32 (2), 135-141.

117. Lovell, P.A.; Schork, F. J., Biomacromolecules. 2020, 21 (11), 4396-4441.

118. Odian, G., John Wiley \& Sons., 2004.

119. González, I.; Leiza, J. R.; Asua, J. M.,. Macromolecules., 2006, 39 (15), 5015-5020.

120. Vanderhoff, J. W. Journal of Polymer Science: Polymer Symposia, Wiley Online Library., 1985, 161-198.

121. Ballard, N.; Asua, J. M., Progress in Polymer Science., 2018, 79, 40-60.

122. Hua, C.; Chen, K.; Wang, Z.; Guo, X., Progress in Organic Coatings., 2020, 143, 105628.

123. Ahmad, N. M.; Heatley, F.; Lovell, P. A., Macromolecules., 1998, 31 (9), 2822-2827.

124. Toniolo, L.; Poli, T.; Castelvetro, V.; Manariti, A.; Chiantore, O.; Lazzari, M., Journal of cultural Heritage., 2002, 3 (4), 309-316. 
125. Benyahia, B.; Latifi, M. A.; Fonteix, C.; Pla F.; Nacef, S., Emulsion copolymerization of styrene and butyl acrylate in the presence of a chain transfer agent.: Part 1: Modelling and experimentation of batch and fedbatch processes. Chemical Engineering Science., 2010, 65 (2), 850-869.

126. Cho, I.; Lee, K. W., Journal of applied polymer science., 1985, 30 (5), 1903-1926.

127. Guillaume, J.; Pichot, C.; Guillot, J, Journal of Polymer Science Part A: Polymer Chemistry., 1988, 26 (7), 1937-1959.

128. Goldwasser, J.; Rudin, A, Polymer Chemistry Edition., 1982, 20 (8), 1993-2006.

129. Anirudhan, T. S.; Shainy, F.; Christa, J, Journal of hazardous materials., 2017, 324, 117-130.

130. Cervantes-Uc, J. M., Cauich-Rodríguez, J. V., Vázquez-Torres, H., \& Licea-Claveríe,A. Polymer degradation and stability., 2006, 91(12), 3312-3321.

131. Pardini, O. R., \& Amalvy, J. I. Journal of Applied Polymer Science., 2008, 107(2), 1207-1214.

132. Moharram, M. A., \& Allam, M. A. Journal of applied polymer science., 2007, 105(6), 32203227.
133. Mukhopadhyay, S. K., Basu, D., \& Banerjee, A. Journal of applied polymer science., 1997, 65(11), 2075-2080.

134. McNeill, I. C., \& Sadeghi, S. M. T. Polymer degradation and stability., 1990, 29(2), 233246.

135. Leskovac, M., Kovačević, V., Flě, D., \& Hace, D. Polymer Engineering \& Science., 1999, 39(3), 600-608.

136. Greenberg, A. R., \& Kusy, R. P. Journal of Applied Polymer Science., 1980, 25(8), 17851788.

137. Rabie, S. M., Sawaby, A., Moharam, M. A., Nassar, A. M., \& Tahon, K. H. Journal of applied polymer science., 1990, 41(3-4), 445-453.

138. Maurer, J. J., Eustace, D. J., \& Ratcliffe, C. T. Thermal characterization of poly (acrylic acid). Macromolecules., 1987, 20(1), 196202.

139. Brown, C. E., Wilkie, C. A., Smukalla, J., Cody Jr, R. B., \& Kinsinger, J. A. Journal of Polymer Science Part A: Polymer Chemistry., 1986, 24(6), 1297-1311.

140. McNeill, I. C., \& Liggat, J. J. Polymer degradation and stability., 1992, 36(3), 291299. 